\title{
PENERAPAN SISTEM PENDUKUNG KEPUTUSAN PENERIMAAN DANA BANTUAN OPERASIONAL SEKOLAH PADA SISWA SMA N 1 SIDOMULYO MENGGUNAKAN METODE TOPSIS BERBASIS WEB
}

\author{
Senna Fernanda ${ }^{1)}$, Yusra Fernando ${ }^{2)}$ \\ ${ }^{1,2)}$ Informatika, Universitas Teknokrat Indonesia \\ Jl. H.ZA Pagaralam, No 9-11, Labuhanratu,Bandarlampung \\ Email : ennananda11@gmail.com ${ }^{1)}$,yusra.fernando@teknokrat.ac.id ${ }^{2)}$
}

\begin{abstract}
Abstrak
Menurut Peraturan Mendiknas nomor 69 Tahun 2009, BOS adalah program pemerintah yang pada dasarnya adalah untuk penyediaan pendanaan biaya operasi nonpersonalia bagi satuan pendidikan dasar sebagai pelaksana program wajib belajar. Adapun permasalahan yang terjadi saat ini dalam melakukan penentuan penerimaan siswa penerima bantuan operasiobal sekolah berupa beasiswa yang terjadi saat ini pada SMAN 1 Sidomulyo, Lampung Selatan adalah masih belum tercapainya standar penilaian kelayakan agar dapat dan wajib menerima bantuan operasional sekolah tersebut, Aplikasi yang dirancang dan yang akan diimplementasikan ini didukung dengan Metode TOPSIS, menggunakan metode pengembangan waterfall dan diimplementasikan dengan Flowchart, Diagram Konteks, Data Flow Diagram, Entity Relationship Diagram, Relasi Tabel, Spesifikasi Tabel, dan menggunakan aplikasi Adobe serta Basis Data MySQL, sebagai database yang dirancang menjadi lebih baik.
\end{abstract}

Kata kunci: TOPSIS, Sistem Pendukung Keputusan, Beasiswa..

\section{Pendahuluan}

SMA Negeri (SMAN) 1 Sidomulyo, Lampung Selatan, merupakan salah satu sekolah menengah atas negeri yang ada di Provinsi Lampung. Sama dengan SMA pada umumnya di Indonesia masa pendidikan sekolah di SMAN 1 Sidomulyo, Lampung Selatan ditempuh dalam waktu tiga tahun pelajaran, mulai dari Kelas X sampai Kelas XII. Terdiri dari dua jurusan yaitu IPA dan IPS, SMAN Sidomulyo, Lampung Selatan memiliki hampir seribu murid yang dikelola oleh sekolah ini.

Adapun permasalahan yang terjadi saat ini dalam melakukan penentuan penerimaan siswa penerima bantuan operasiobal sekolah berupa beasiswa yang terjadi saat ini pada SMAN 1 Sidomulyo, Lampung Selatan adalah masih belum tercapainya standar penilaian kelayakan agar dapat dan wajib menerima bantuan operasional sekolah tersebut, dikarenakan faktor kedekatan dengan pihak oknum terkait maupun pihak internal dari SMAN 1 Sidomulyo, Lampung Selatan menyebabkan standar penilaian kelayakan masih berdasarkan faktor subjektifitas, lalu tindak manipulasi data merupakan hal yang paling sering terjadi pada saat pembuatan laporan data penerima bantuan operasional sekolah berupa beasiswa pada SMAN 1 Sidomulyo, Lampung Selatan, kemudian dalam pengolahan datanya masih menggunakan cara konvensional, dimana dalam melakukan pencatatan dan pengolahan berkas penerimaan bantuan operasional sekolah pada SMAN 1 Sidomulyo, Lampung Selatan, penyimpanan data sudah menggunakan tools Microsoft Excel namun faktor keamanan data menjadi salah satu faktor yang rentan dikarenakan tidak adanya pembatasan akses dalam penggunaanya, kemudian apabila terjadi kerusakan pada hardware akan menyebabkan hilangnya data dan dalam melakukan pembuatan laporan penerimaan bantuan operasional sekolah pada SMAN 1 Sidomulyo, Lampung Selatan, masih membutuhkan waktu yang lama dikarenakan harus memeriksa dan mencari satu per satu berkas yang ada pada SMAN 1 Sidomulyo, Lampung Selatan, terkait data penerimaan bantuan operasional sekolah.

\section{Rumusan Masalah}

Bagaimana membantu pihak tata usaha pada SMA N Sidomulyo dalam merancang Sistem Pendukung Keputusan Penerimaan Dana Bantuan Operasional Sekolah menggunakan metode topsis berbasis web dalam menentukan kelayakan siswa penerima bantuan operasional sekolah bantuan beasiswa secara objektifitas ?

Batasan Masalah

Penulis memberikan batasan masalah pada pembahasan dalam penelitian ini, agar pembahasannya tidak terlalu luas atau menyimpang. Penelitian ini hanya dibatasi pada:

1. Sekolah yang menjadi objek penelitian adalah SMA N 1 Sidomulyo, Lampung Selatan.

2. Metode sistem pendukung keputusan yang akan digunakan adalah Technique for Order Preference by Similarity to Ideal Solution (TOPSIS)

3. Kriteria penilaian berdasarkan standar kelayakan siswa penerima bantuan operasional sekolah yang diberikan Menteri Pendidikan Nasional.

Tujuan Penelitian

Adapun tujuan dari penelitian ini adalah membangun suatu sistem penentuan menu utama dengan menerapkan metode Weighted Product (WP) adalah: 
1. Untuk membantu meminimalisir tindak manipulasi data siswa penerimaan bantuan operasional sekolah pada SMA N 1 Sidomulyo, Lampung Selatan.

2. Untuk menerapkan penggunaan teknologi informasi dalam memberikan rekomendasi hasil dari penentuan kelayakan siswa penerima bantuan operasional sekolah pada SMA N 1 Sidomulyo, Lampung Selatan.

\section{Pembahasan}

\section{TOPSIS}

Menurut Sachdeva (2009) Technique for Order Preference by Similarity to Ideal Solution (TOPSIS) adalah :

"Merupakan metode yang akan merangking alternatif berdasarkan prioritas nilai kedekatan relatif suatu alternatif terhadap suatu solusi ideal positif. Alternatif - alternatif yang telah dirangking kemudian dijadikan sebagai referensi bagi pengambil keputusan".

Langkah - langkah penyelesaian masalah MADM dengan TOPSIS :

a. Membuat matriks keputusan yang ternormalisasi.

$$
r_{i j}=\frac{x i j}{\sqrt{\sum_{i=1}^{M m} x_{i j}^{2}}}
$$

b. Membuat matriks keputusan yang ternormalisasi terbobot.

$y_{i j}=\mathrm{w}_{i} \mathrm{r}_{i j}$

c. Menentukan matriks solusi ideal positif \& matriks solusi ideal negatif.

$A^{+}=\left(y_{1}^{+}, y_{2}^{+}, \ldots, y_{n}^{+}\right)$;

$A-\quad=\left(y_{1}^{-}, y_{2}^{-}, \ldots, y_{n}^{-}\right)$;

$y_{1}^{+}$

\{

max1Yij : jika J adalah atribut keuntungan min1 Yij : jika J adalah atribut biaya

$y_{1}^{-}$

min1 $Y i j$ : jika J adalah atribut keuntungan $\max 1 Y i j$ : jika J adalah atribut biaya

d. Menentukan jarak antara nilai setiap alternatif dengan matriks solusi ideal positif \& matriks solusi ideal negatif.

$$
\begin{aligned}
& D_{i}^{+}=\sqrt{\sum_{j=1}^{n}\left(Y_{i}^{+}-y_{i j}\right)^{2}} \\
& D_{i}^{-}=\sqrt{\sum_{j=1}^{n}\left(Y_{i j}-y_{i}^{-}\right)^{2}}
\end{aligned}
$$

e. Menentukan nilai preferensi untuk setiap nilai alternatif.

$$
\mathrm{V}_{\mathrm{i}}=\frac{D_{\mathrm{i}-}}{D_{\mathrm{i}}^{-}+D_{\mathrm{i}}^{+}}
$$

\section{Sistem Pendukung Keputusan}

Menurut Alter (2002), Sistem pendukung keputusan merupakan sistem informasi interaktif yang menyediakan informasi, pemodelan, dan pemanipulasian data. Sistem itu digunakan untuk membantu pengambilan keputusan dalam situasi yang semiterstruktur dan situasi yang tidak terstruktur, di mana tak seorang pun tahu secara pasti bagaimana keputusan seharusnya dibuat.

Menurut McLeod (2005), sistem pendukung keputusan merupakan sebuah sistem yang menyediakan kemampuan untuk penyelesaian masalah dan komunikasi untuk permasalahan yang bersifat semiterstruktur.

Menurut Kusrini (2007), sistem pendukung keputusan dibangun untuk mendukung solusi atas suatu masalah atau untuk mengevaluasi suatu peluang. Sistem pendukung keputusan yang seperti itu disebut aplikasi sistem pendukung keputusan. Aplikasi sistem pendukung keputusan digunakan dalam pengambilan keputusan. Aplikasi sistem pendukung keputusan menggunakan CBIS (Computer Based Information System) yang fleksibel, interaktif, dan dapat diadaptasi, yang dikembangkan untuk mendukung solusi atas

\begin{tabular}{|c|c|c|c|}
\hline Kode & $\begin{array}{c}\text { Kriteria / } \\
\text { Variabel } \\
\end{array}$ & Subkriteria & Nilai \\
\hline \multirow{4}{*}{$\mathrm{C} 1$} & \multirow{4}{*}{$\begin{array}{l}\text { Faktor } \\
\text { Ekonomi }\end{array}$} & Kurang & 25 \\
\hline & & Cukup & 50 \\
\hline & & Baik & 75 \\
\hline & & Sangat Baik & 100 \\
\hline \multirow{4}{*}{$\mathrm{C} 2$} & \multirow{4}{*}{ Kedisiplinan } & Kurang & 25 \\
\hline & & Cukup & 50 \\
\hline & & Baik & 75 \\
\hline & & Sangat Baik & 100 \\
\hline \multirow{4}{*}{$\mathrm{C} 3$} & \multirow{4}{*}{ Prestasi Siswa } & Kurang & 25 \\
\hline & & Cukup & 50 \\
\hline & & Baik & 75 \\
\hline & & Sangat Baik & 100 \\
\hline \multirow{2}{*}{$\mathrm{C} 4$} & \multirow{2}{*}{$\begin{array}{l}\text { Kegiatan } \\
\text { Extrakulikuler }\end{array}$} & Tidak Aktif & 50 \\
\hline & & Aktif & 100 \\
\hline \multirow{4}{*}{$\mathrm{C} 5$} & \multirow{4}{*}{ Kehadiran } & Kurang & 25 \\
\hline & & Cukup & 50 \\
\hline & & Baik & 75 \\
\hline & & Sangat Baik & 100 \\
\hline
\end{tabular}
masalah manajemen spesifik yang tidak terstruktur.

\section{Metode Weighted Product (WP)}

Tabel 1. Kriteria 
Tabel 2. Subkriteria

\begin{tabular}{|c|l|c|}
\hline Kode & Kriteria / Variabel & Bobot (W) \\
\hline C1 & Faktor Ekonomi & $30 \%$ \\
\hline C2 & Kedisiplinan & $25 \%$ \\
\hline C3 & Prestasi Siswa & $20 \%$ \\
\hline C4 & $\begin{array}{l}\text { Kegiatan } \\
\text { Extrakulikuler }\end{array}$ & $10 \%$ \\
\hline C5 & Kehadiran & $15 \%$ \\
\hline
\end{tabular}

\section{Diagram Konteks (Context Diagram)}

Tahap Context Diagram terdapat 3 entitas yang berperan yaitu Wali Kelas, Waka Kurikulum dan Kepala Sekolah. Context Diagram Penerapan Sistem Pendukung Keputusan Penerimaan Dana Bantuan Operasional Sekolah Pada Siswa SMA N 1 Sidomulyo Menggunakan Metode Topsis Berbasis Web dapat dilihat pada gambar dibawah ini :

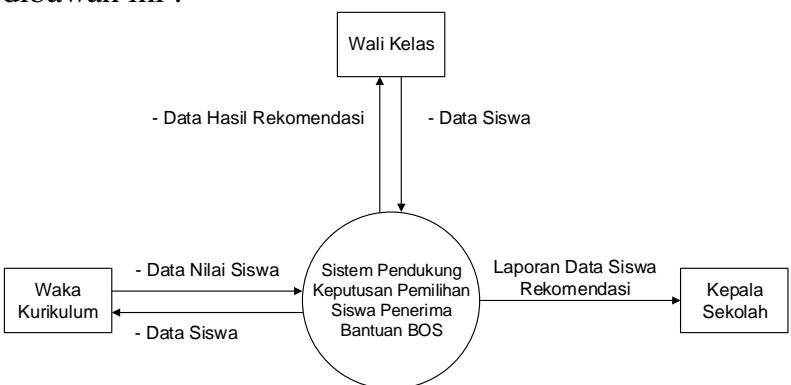

Sistem Rancangan Diagram Context (Diagram Konteks)

\section{Diagram Alir Data (Data Flow Diagram)}

Data Flow Diagram (DFD) merupakan gambaran dari suatu sistem secara logika yang tidak tergantung terhadap perangkat keras, perangkat lunak, struktur data atau organisasi file, dengan adanya DFD maka pemakai sistem yang kurang memahami dibidang komputer dapat mengerti sistem yang sudah berjalan. Diagram Alir Data Level 0 Penerapan Sistem Pendukung Keputusan Penerimaan Dana Bantuan Operasional Sekolah Pada Siswa SMA N 1 Sidomulyo Menggunakan Metode Topsis Berbasis Web dapat dilihat pada gambar di bawah ini :

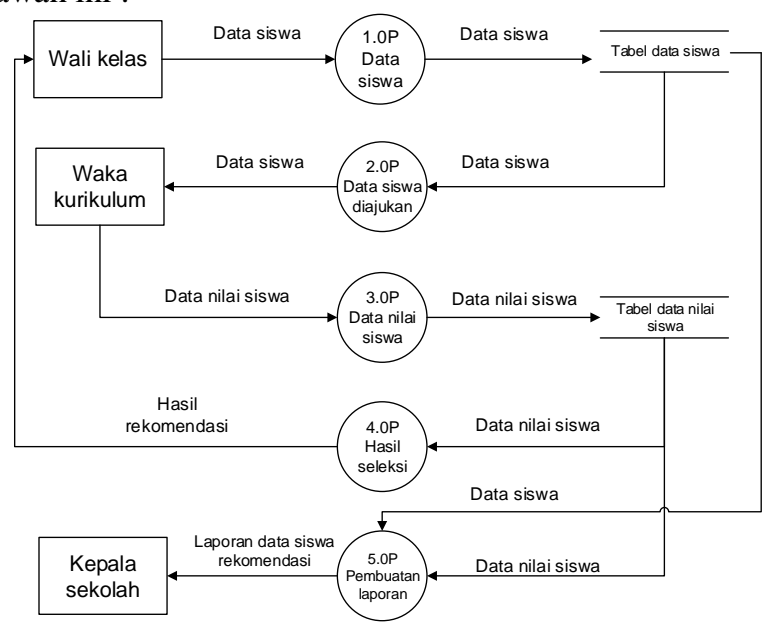

Sistem Rancangan Data Flow Diagram (DFD) Level 0

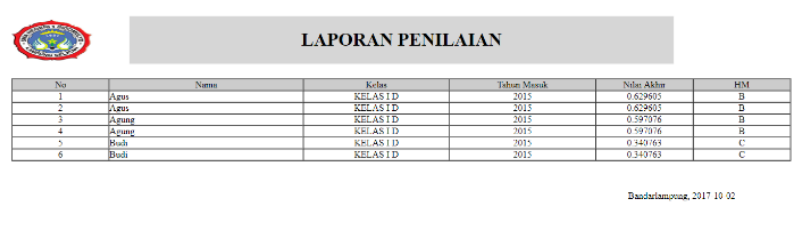

Gambar Hasil perhitungan TOPSIS

\section{Kesimpulan}

Dengan adanya Penerapan Sistem Pendukung Keputusan Penerimaan Dana Bantuan Operasional Sekolah Pada Siswa SMA N 1 Sidomulyo Menggunakan Metode Topsis Berbasis Web dapat mempermudah dan mempercepat proses penghitungan kelayakan penerima bantuan secara objective sesuai dengan SOP yang dimiliki oleh sekolah, karena melalui tahapan perbandingan pada kriteria dan sub kriteria yang dimiliki perusahaan sebagai landasan SOP dalam penilaian kelayakan siswa dengan penghitungan metode TOPSIS.

\section{Daftar Pustaka}

Alter, 2002, Konsep dan Aplikasi Sistem Pendukung Keputusan,Andi,Yogyakarta.

Al Fatta, Hanif. 2011, Analisis danPerancangan Sistem Informasi, Andi, Yogyakarta.

A.S Rosa, S., 2014. Modul Rekayasa Perangkat Lunak Terstruktur Dan Berorientasi Objek. Bandung: Modul.

Hartanto, 2014, Aplikasi Sistem Sumber Daya Manusia Dengan Fitur Dss Menggunakan Metode TOPSIS pada PT $X$, Jurnal Universitas Kristen Maranatha

Indriati, 2014, Sistem Pendukung Keputusan Penerimaaan Pegawai Mikro Kredit Sales ( $M K S$ ) Menggunakan Metode AHP dan TOPSIS, Jurnal Universitas Brawijaya

Isnanto, 2014, Penerapan Metode AHP dan Fuzzy TOPSIS Untuk Sistem Pendukung Keputusan Promosi Jabatan, Jurnal Universitas Pekalongan

Jogiyanto, 2014, Analisis dan Desain Sistem Informasi : Pendekatan Terstruktur Teori dan Praktek Aplikasi Bisnis, Andi, Yogyakarta.

Kadir, 2014, Pengenalan Sistem Informasi, Andi, Bandung.

Kusrini,2007,Konsep dan Aplikasi Sistem Pendukung Keputusan,Yogyakarta,Andi

Ladjamuddin, bin Al-Bahra, 2013, Analisis dan Desain Sistem Informasi Graha Ilmu, Yogyakarta.

McLeod, 2005, Management Information System, Texas, United States Of America.

Peraturan Mendiknas nomor 69 Tahun (2009).

Rachman, 2008, Sistem Pendukung Keputusan Seleksi Sumber Daya Manusia pada Perusahaan, Jurnal Institut Teknologi Adhi Tama Surabaya. 
Romney, 2011, Manajemen Sistem Informasi, Boston, United States Of America.

Saelindri, 2014, Sistem Pendukung Keputusan Untuk Menentukan Kelayakan Penerimaan Bantuan Siswa Miskin (BSM) Dengan Menggunakan Metode TOPSIS

Sommerville, 2011, Manajemen Sistem Informasi, Boston, United States Of America. 